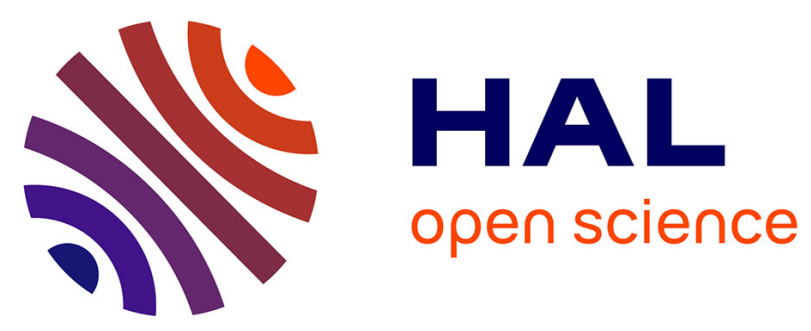

\title{
A high variability of arterial Doppler waveform descriptions exists in China
}

Chaoyang Wen, Meiying Gao, Yuwei Fu, Rui Zhao, Yisha Tong, Robert Scissons, Damien Lanéelle, Guillaume Mahé

\section{To cite this version:}

Chaoyang Wen, Meiying Gao, Yuwei Fu, Rui Zhao, Yisha Tong, et al.. A high variability of arterial Doppler waveform descriptions exists in China. Vascular Medicine, 2020, 25 (3), pp.221-222. 10.1177/1358863X20903808 . hal-02532958

\section{HAL Id: hal-02532958}

\section{https://hal-univ-rennes1.archives-ouvertes.fr/hal-02532958}

Submitted on 15 May 2020

HAL is a multi-disciplinary open access archive for the deposit and dissemination of scientific research documents, whether they are published or not. The documents may come from teaching and research institutions in France or abroad, or from public or private research centers.
L'archive ouverte pluridisciplinaire HAL, est destinée au dépôt et à la diffusion de documents scientifiques de niveau recherche, publiés ou non, émanant des établissements d'enseignement et de recherche français ou étrangers, des laboratoires publics ou privés. 
Title: A high variability of arterial Doppler waveforms description exists in China

Author list: C Wen ${ }^{1}, \mathrm{M} \mathrm{Gao}^{1}$, Y Fu ${ }^{1}$, R Zhao ${ }^{1}$, Y. Tong ${ }^{2}$, R. Scissons ${ }^{3}$, D. Lanéelle ${ }^{4}$, G. Mahé $^{5,6}$

Dr Wen and Dr Gao contributed equally to this work.

1: Department of Ultrasound, Peking University International Hospital, Beijing, China

2: Department of Vascular Surgery, Austin Hospital, Melbourne, Australia

3: Jobst Vascular Center Laboratory, Toledo, USA.

4: Université de Caen, Centre Hospitalier Universitaire (CHU) de Caen Normandie, Service de Médecine Vasculaire, INSERM Comete, Caen, France

5: Université de Rennes 1, INSERM CIC 1414, Rennes, France

6: Department of Vascular Medicine, CHU Rennes, Rennes, France

Correspondence to:

\section{Guillaume MAHE, MD-PhD}

Vascular Medicine and Investigation Department

INSERM CIC-1414. Pôle imagerie médicale et explorations fonctionnelles

Hôpital Pontchaillou, 2 rue Henri Le Guilloux. Rennes, F-35033. France

Tel: +33 (0)2 99284321

Fax: +33 (0)2 99284364

E-mail: maheguillaume@yahoo.fr

Keywords: Doppler Waveforms, Peripheral Artery Disease, Duplex Ultrasound, Doppler Classification, vascular imaging/diagnostics

Word Count: Main Body: 795 


\section{MAIN BODY}

Doppler ultrasound is standardly used for non-invasive evaluation of peripheral artery disease (PAD). The analysis of Doppler ultrasound waveforms provides a method for detecting and evaluating arterial stenosis in peripheral arteries [1, 2].

We have previously demonstrated in France that there is significant heterogeneity of description of Doppler waveforms by vascular residents [3]. However, the heterogeneity of describing Doppler waveforms was significantly reduced when using a 4-item Doppler classification [3, 4].

This study aimed to assess the heterogeneity of Doppler waveforms description among Chinese sonologists and the impact of the use of a 4-item Doppler classification.

During a national annual ULTRASOUND CONGRESS in Beijing (May 5-6 ${ }^{\text {th }}$, 2019) sonographer attendees were invited to fill an online questionnaire developed by Scissons [5]. The questionnaire contained thirty Doppler waveforms [3]. Attendees were invited first to describe 30 Doppler waveforms (15 pulsed ultrasound waveforms (PW) and 15 continuous ultrasound waveforms (CW)) as usual in their clinical practice (first round). Second, they have to describe the same 30 Doppler waveforms using a 4-item classification (triphasic, biphasic, and monophasic and others) (second round). This study was validated by the ethical committee of Rennes (France) and registered on clinicaltrials.gov (NCT03827512).

We used a Wilcoxon-test to compare the heterogeneity of the responses between the first round and the second round. Comparisons of correct answers (in percent) were compared using Chi-squared test. Statistical analyses were made using $\mathrm{R}$ software (http://www.R-project.org). A two-tailed $p$-value $<0.05$ was considered as statistically significant. 
Two hundred and nine participants from 23 provinces in China (Figure 1a) were included in the study: 128 in the first round, 178 in the second and 97 participated in both rounds. Median number of years working in vascular ultrasound was 7[4-7] years. Among the 209 participants, participants who worked in primary hospital secondary hospital and tertiary hospital were 10, 59 and 140 respectively. Among the 209 participants, 137 have bachelor's degrees, 58 have master's degrees, 3 have doctoral degrees, and 11 have associated degrees.

There was no significant difference in the number of different free answers between participants with experience of more than seven years and participants with experience of 1-7 years $(\mathrm{p}>0.05)$. In the first round among 128 participants, the average of different free responses was $51.2 \pm 10.5$. Among the 97 participants who participated in both the first and second rounds, the average of different responses was $40.1 \pm 8.0$ for the interpretation without classification and $3.4 \pm 0.8$ with a suggested 4-item classification for the whole analysis of the 30 Doppler waveforms (Figure $1 \mathrm{~b}, \mathrm{p}<0.05$ ). Among the overall Doppler waveforms, the mean of correctly identified Doppler waveforms was $76 \%$ (range $9 \%-100 \%$ ) among the 97 participants. There was no statistical difference between average of correct answers for all PW and average for all CW (p > 0.05).

Scissons has previously reported that the description of Doppler waveforms is an issue in the United States of America [5]. Our previous work realized in France found also that there was a huge heterogeneity in the description on the Doppler waveforms [3]. There are several possible explanations: first there is a lack of an international consensus defining the way of Doppler waveforms description. Indeed Doppler waveforms analysis is proposed as an easy means of diagnosis peripheral artery disease 
[6], but no recommendation has proposed Doppler classification that should be used. Second, as shown by Nicolaïdes and Yao [7], a same word can be used for the description of different Doppler waveforms in the literature. This contributes to maintain the confusion in the ultrasound practice.

Of interest, in our present study, the percentage of correct answers (76\%) about the Doppler waveforms was similar than the percentage previously reported by Scissons (74\%) suggesting that the level of ultrasound knowledge of these Chinese sonographers is nearly similar as the level of the American sonographers [5]. This number of correct answers is slightly lower than the results obtained in France but the number of French residents was low $(n=19)$ [3].

Finally, in this study we also show that the number of different answers is statistically reduced using a classification as previously found [3]. It could be of interest to see whether or not similar results are found with other classification such as the SaintBonnet Classification [2].

The present study shows the importance to standardize reporting of Doppler waveforms and demonstrates that there is significant heterogeneity of description of Doppler waveforms by Chinese sonographers. The use of a dedicated classification has allowed reducing the numbers of terms used for the Doppler waveforms description. This improvement of reporting Doppler waveforms and the high percentage of correctly classified waveforms when using a predefined set of terms illustrate that there is an urgent need to standardize the Doppler waveform description in order to improve the clinical management of patient with PAD. 


\section{DISCLOSURE}

\section{Acknowledgements}

The authors thank the sonologists and sonographers for their participation in this study.

\section{Conflicts of Interests}

The authors declared no potential conflicts of interest with respect to the research, authorship, and/or publication of this article.

\section{Funding}

The Beijing Natural Science Foundation (7172209) supported this work. 


\section{References}

[1] Mahé G, Boulon C, Désormais I, Lacroix P, Bressollette L et al. College of the French Vascular Medicine Teachers statement: Arterial Doppler waveforms analysis, simplified Saint-Bonnet classification. J Med Vasc. 2018 Jul;43(4):255-261. doi: 10.1016/j.jdmv.2018.05.002.

[2] Mahé G, Boulon C, Desormais I, Lacroix P, Bressollette L, Guilmot J-L, et al. Statement for Doppler waveforms analysis. VASA Z Gefasskrankheiten. 2017:1-9.

[3] Omarjee L, Stivalet O \& Hoffmann C, et al. Heterogeneity of Doppler waveform description is decreased with the use of a dedicated classification. Vasa 2018; 47(6):471-474.

[4] Scissons R \& Comerota A. Confusion of Peripheral Arterial Doppler Waveform Terminology. J Diagn Med Sonogr. 2009;25:185-94.

[5] Scissons R. Characterizing Triphasic, Biphasic, and Monophasic Doppler Waveforms: Should a Simple Task Be So Difficult? J Diagn Med Sonog 2008;24:269_ 276.

[6] Gerhard-Herman MD, Gornik HL, Barrett C, Barshes NR, Corriere MA \& Drachman DE, et al. 2016 AHA/ACC Guideline on the Management of Patients With Lower Extremity Peripheral Artery Disease: A Report of the American College of 
Cardiology/American Heart Association Task Force on Clinical Practice Guidelines. Circulation. 2017;135:e726-79.

[7] Nicolaides, Andrew N; Yao, James S T. Investigation of vascular disorders. New York : Churchill Livingstone, 1981.

[8] Descotes J \& Cathignol D. Classification of changes in circulatory rate in the arteries of the lower limbs. Transcutaneous measurement by Doppler effect. Nouv Presse Med. 1975;4:2091-3.

[9] Spronk S, den Hoed PT, de Jonge LCW, van Dijk LC \& Pattynama PMT. Value of the duplex waveform at the common femoral artery for diagnosing obstructive aortoiliac disease. J Vasc Surg. 2005;42:236-42.

Figure 1.

1a. Regional distribution of the congress attendees

1b. Heterogeneity comparison. Number of different responses of the 30 Doppler waveforms among 97 participants who completed both rounds with and without suggested classification.

$1 \mathrm{a}$

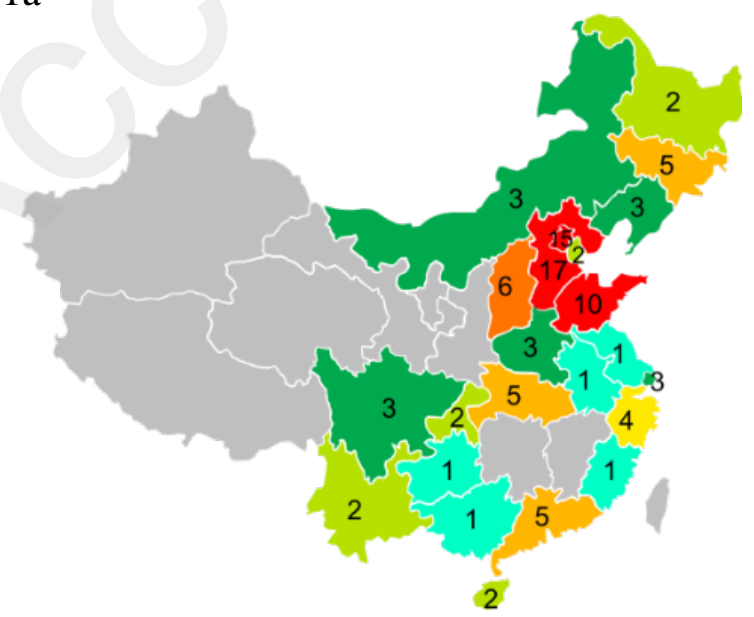

$1 b$

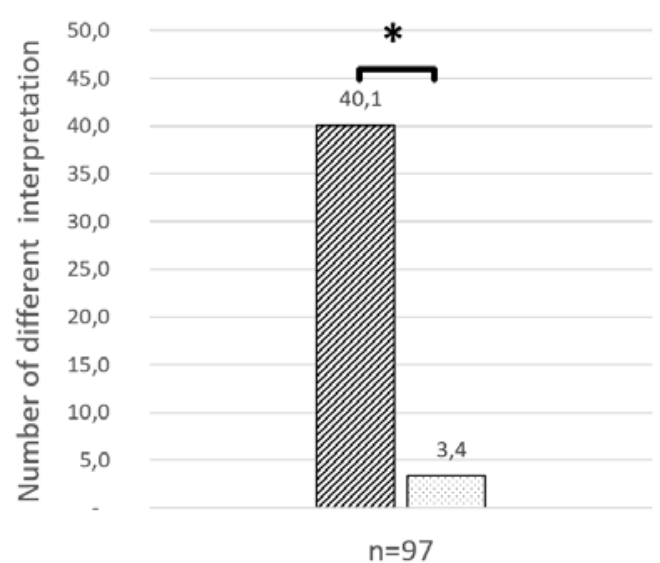

Without suggested classification (first round)

$\square$ With 4-item classification (second round) 